\title{
Green synthesis and spectral analysis of surface encapsulated copper (II) oxide nanostructures
}

\author{
ARUN S. PRASAD* \\ Post Graduate Department of Physics, TKMM College, Nangiarkulangara, Alappuzha, Kerala-690513, India
}

\begin{abstract}
Nanostructures of copper (II) oxide were synthesized through chemical reduction of copper (II) sulfate pentahydrate using phytochemicals present in leaf extracts of Leucas aspera. The crystalline phases and size were assessed by X-ray diffraction data analysis. From the Bragg reflection peaks, existence of monoclinic end-centered phase of copper (II) oxide along with presence of cubic primitive phase of copper (I) oxide and traces of cubic face centered lattices of zero valent copper was revealed. The three Raman active modes corresponding to $\mathrm{CuO}$ phase were identified in the sample with permissible merging of characteristic bands due to nanostructuring and organic capping. The surface topography measurement using field emission scanning electron microscope evidenced the occurrence of cylindrical rod shaped morphological structures along with a number of unshaped aggregates in the sample. The effective crystallite size and lattice strain were estimated from Williamson-Hall analysis of Bragg reflection data. Tauc plot analysis of UV-Vis-NIR absorption data in direct transition mode provided an estimation of band gap, viz. $1.83 \mathrm{eV}$ and $2.06 \mathrm{eV}$ respectively, for copper (II) oxide and copper (I) oxide. Thermal degradation study using thermogravimetric curve analysis could reveal the amount of moisture content, volatile components as well as the polymer capping over nanorods present in the sample. It could be seen that upon heating, inorganic core crystals undergo oxidation process and at temperature above $464{ }^{\circ} \mathrm{C}$, the sample was found to be composed solely of inorganic crystallite phase of copper (II) oxide.
\end{abstract}

Keywords: nanostructures; phytochemicals; Leucas aspera; thumbe; monoclinic

\section{Introduction}

Tunable physical and chemical properties can be incorporated into metal oxide micro/nanostructures via appropriate synthesis techniques yielding compositions with unique structure, controllable size and morphology, etc. [1-7]. Recently, uncomplicated bottom up chemical routes were accomplished for synthesis of such nanostructures with suitable morphology, size and yield [1, 8, 9]. Among simple transition metal oxide nanocrystals, oxides of copper have gained fabulous interest among materials researchers [1, 10-12]. Bulk $\mathrm{CuO}$, being the p-type semiconductor with a narrow band gap ranging from $1.2 \mathrm{eV}$ to $1.5 \mathrm{eV}$ [13], was already reported as a useful candidate in many fields including catalysis [14-16], gas sensors [17], supercapacitors [18], anode material in Li-ion batteries and photoelectric materials [19]. Copper

\footnotetext{
*E-mail: asp.physics@gmail.com
}

oxide nano/microstructures with different morphological shapes, such as nanowires, nanorods, flowers, etc., have been reported by various researchers [1, 20-31]. Variety of such nanostructures were synthesized using various techniques such as solution-based methods [32], microwave irradiation [33], solvothermal processes [34], hydrothermal methods [35], electrodeposition [36], wet chemical reduction [37] etc. Liu and Zeng [38] reported self-organization of $\mathrm{CuO}$ hierarchical microspheres with a puffy appearance. Liu et al. [39] prepared porous $\mathrm{CuO}$ hollow structures based on non-equilibrium interdiffusion process. Zhu et al. [40] synthesized hierarchically porous $\mathrm{CuO}$ structures via a facile hydrothermal route. Jiang et. al. [41] described a vapor-phase approach for the synthesis of hierarchically uniform $\mathrm{CuO}$ nanowire arrays on various copper substrates. Sonia et. al. [29] prepared $\mathrm{CuO}$ nanorods by direct sonochemical method for antimicrobial activities. Yang et. al. [30] synthesized $\mathrm{CuO}$ nanorods by microwave-assisted hydrothermal 
method for gas sensing applications. Wu et al. [31] studied photocatalytic properties of $\mathrm{Cu}_{2} \mathrm{O} / \mathrm{CuO}$ nanorods prepared by two step hydrothermal method. It has been recently found that, aqueous green chemical methods are capable of producing various morphologies of $\mathrm{CuO}$ nanostructures depending on the type of green reductants used and synthesis conditions $[1,10,11,28]$. However, there are still challenges to develop facile green routes for the high yield synthesis of uniform $\mathrm{CuO}$ nanostructures.

In this work, an attempt was made to synthesize $\mathrm{CuO}$ nanostructures through chemical reduction of copper sulfate pentahydrate $\left(\mathrm{CuSO}_{4} \cdot 5 \mathrm{H}_{2} \mathrm{O}\right)$ using the phytochemicals present in the leaf extract of thumbe plant (Botanic name: Leucas aspera). The sample was labeled as Cu-NP-TUMBA for further reference. The plant is coming from Lamiaceae family in Leucas genus. Leucas aspera grows in the southern part of India, especially in states, like Kerala and Karnataka. Analysis of antioxidant efficiency of Leucas aspera revealed that the presence of various phytochemicals including alkaloids, phytosterols, flavonoids, saponins, phenols and glycosides are responsible for its antioxidant properties [42].

\section{Experimental}

\subsection{Materials}

The leaves of thumba (Leucas aspera) were collected in Punalur, the eastern part of Kollam district in Kerala State, India. The precursor salt, $\mathrm{CuSO}_{4} \cdot 5 \mathrm{H}_{2} \mathrm{O}$, was purchased from Merck Life Science Private Limited. The $\mathrm{pH}$ of the solution mixture was maintained using $\mathrm{NaOH}$.

\subsection{Preparation of plant extract}

Fresh leaves were collected and washed several times in demineralized water. Selected leaves were left to dry in sunshade (mid sunlight). The dried leaves were crushed into fine powder and an aqueous solution of leaf extract was prepared in boiled de-mineralized water. The extract was stirred homogeneously, filtered out twice using Whatman filter paper Cat No. 1001-110 and kept cool for further use $[8,9]$.

\subsection{Synthesis of $\mathrm{Cu}-\mathrm{NP}-\mathrm{TUMBA}$ sample}

The reaction mixture was prepared by adding $0.1 \mathrm{M} \mathrm{CuSO}_{4} \cdot 5 \mathrm{H}_{2} \mathrm{O}$ precursor solution into the leaf extract in 2:3 volume ratio under constant stirring and warming according to the procedural steps discussed in the literature $[8,9]$. The $\mathrm{pH}$ was maintained just above 6 by the addition of $0.1 \mathrm{M} \mathrm{NaOH}$ solution. At sufficient $\mathrm{pH}$, the reaction kinetics accelerated and the formation of nano/micro structured clusters was observed with marked color changes. Finally, the obtained crushed fine powder, annealed at $110^{\circ} \mathrm{C}$ for $2 \mathrm{~h}$, was kept labeled as $\mathrm{Cu}-$ NP-TUMBA for further analytical measurements.

\subsection{Characterization and measurement techniques}

Spectroscopic methods, such as X-ray diffraction technique, scanning electron microscopy (FESEM) and micro Raman spectra, were used as tools for characterizing the material sample. The detailed analysis of crystallographic structure, crystallite size, morphology and microstructure was made using these tools. Further, TGA measurement provided information related to thermal behavior of the sample.

\section{Results and discussion}

\subsection{Crystallographic analysis}

Fig. 1 presents X-ray diffraction pattern recorded for the powder sample at SICC, Kariyavattom Campus, University of Kerala, Thiruvananthapuram, Kerala, India. BRUKER D8 ADVANCE diffractometer system with 280 goniometer radius was used for the measurement. An X-ray wavelength of $1.5406 \AA$ was allowed to impinge on the sample in scan angle, $2 \theta$ ranging from $10^{\circ}$ to $90^{\circ}$ in 0.020305 step size [9].

The Bragg reflection peaks obtained were indexed to the planes corresponding to $\left(\begin{array}{lll}1 & 1 & 0\end{array}\right)$,

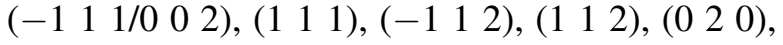

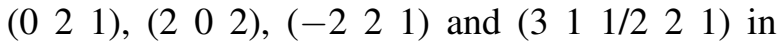
analogy with the monoclinic end-centered phase 


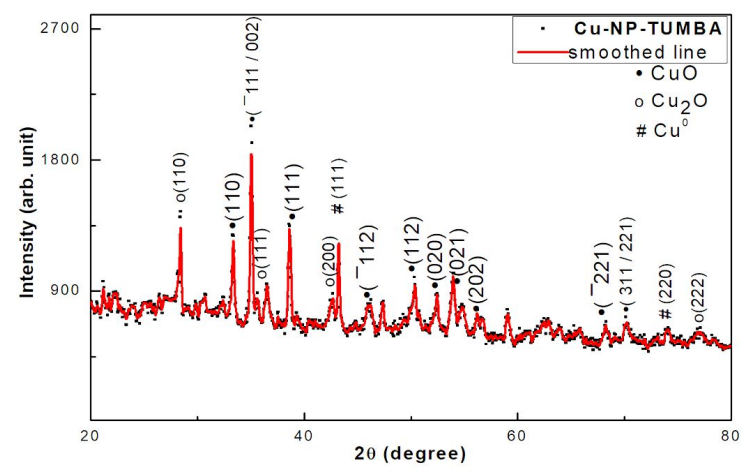

Fig. 1. XRD pattern obtained for Cu-NP-TUMBA.

of copper (II) oxide $(\mathrm{CuO})$ with reference to the JCPDS: ICDD PCPDFWIN \#PDF Number: 802531 under the space group C2/c [15]. Also, the planes corresponding to copper (I) oxide $\left(\mathrm{Cu}_{2} \mathrm{O}\right)$ in cubic primitive phase as referenced by JCPDS: ICDD PCPDFWIN \#PDF Number: 653288 were observed under the space group pn-3m (224). The respective Bragg reflection peaks were indexed to the planes ( $\left.\begin{array}{lll}1 & 1 & 0\end{array}\right),\left(\begin{array}{lll}1 & 1 & 1\end{array}\right),\left(\begin{array}{lll}2 & 0 & 0\end{array}\right)$ and (2 2 2). Additionally, traces of cubic face centered lattices of zero valent copper $\left(\mathrm{Cu}^{0}\right)$ were observed with corresponding lattice planes indexed to (lll 111$)$ and (2 220$)$ with reference to JCPDS: ICDD PCPDFWIN \#PDF Number: 851326 under the space group Fm-3m (225).

Considerably broadened X-ray reflection peaks from various crystallographic planes indicate the distribution of crystallite size in nanometric regime. Further, it is apparent from the XRD pattern that the fractional area under the peaks corresponding to $\mathrm{CuO}$ phase is greater compared to other phases, such as $\mathrm{Cu}_{2} \mathrm{O}$ and $\mathrm{Cu}^{0}$, indicating the dominance of monoclinic end- centered $\mathrm{CuO}$ in Cu-NP-TUMBA sample.

\subsection{Micro-Raman analysis}

Micro-Raman spectrum was recorded for the sample at an excitation wavelength of $514 \mathrm{~nm}$, using LabRAM HR instrument installed at Department of Optoelectronics, University of Kerala. From the XRD pattern, the main phase of the sample was revealed as $\mathrm{CuO}$, which is a semiconducting material that crystallizes in a monoclinic structure. The primitive cell contains two molecular units and thus there exist twelve vibration modes at the zone center including three acoustic modes, six infrared active modes and three Raman active modes $\left(a_{g}+2 b_{g}\right)$. These normal lattice vibrations at the point of Brillouin zone could be realized on the basis of group theory. Because of site symmetry, only oxygen atom displacement contributes to the Raman modes and thus the $\mathrm{Cu}$ atoms remain stationary in these three modes. Out of the three Raman modes, $a_{\mathrm{g}}$ mode occurs at the band around $280 \mathrm{~cm}^{-1}$ and the two $\mathrm{b}_{g}$ modes occur at the bands around $330 \mathrm{~cm}^{-1}$ and $619 \mathrm{~cm}^{-1}$, respectively.

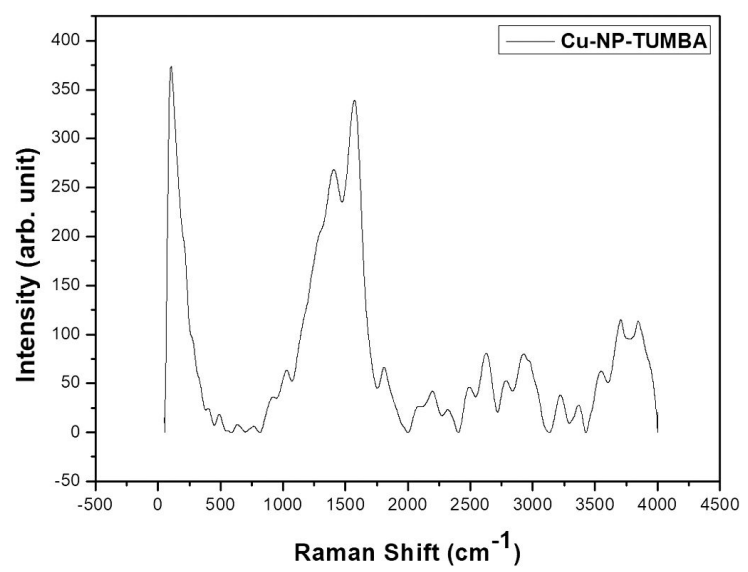

Fig. 2. Micro Raman spectrum of Cu-NP-TUMBA.

However, in the present case, the formation of $\mathrm{CuO}$ in nanocrystalline form along with traces of other phases such as $\mathrm{Cu}_{2} \mathrm{O}$ and $\mathrm{Cu}^{0}$ and the organic capping could affect the scattering modes in different ways. As a consequence, the merging among bands with other phases was possible and it is evident from Fig. 2 that $\mathrm{a}_{\mathrm{g}}$ band at $280 \mathrm{~cm}^{-1}$ has merged with $b_{g}$ band at $330 \mathrm{~cm}^{-1}$ of $\mathrm{CuO}$ phase along with $\mathrm{Cu}_{2} \mathrm{O}$ phases. The $\mathrm{b}_{\mathrm{g}}$ mode at $619 \mathrm{~cm}^{-1}$ is diminished. The band at $1399 \mathrm{~cm}^{-1}$ attributed to the methyl group in organic capping has merged with one of the $\mathrm{Cu}_{2} \mathrm{O}$ bands at $1552 \mathrm{~cm}^{-1}$.

\subsection{Morphological analysis}

Fig. 3 shows field emission scanning electron microscope (FE-SEM) patterns imaged from Nova NanoSEM 450 installed at Department 
of Optoelectronics, University of Kerala. Surface topography analysis of the images at four different magnifications viz., $\times 2000, \times 15,000, \times 50,000$ and $\times 150,000$ clearly evidence the formation of well dispersed long cylindrical rod shaped nanostructures along with a number of unshaped aggregates. In analogy with the dominant $\mathrm{CuO}$ phase, as apparent from crystallographic analysis using $\mathrm{X}$-ray diffraction pattern, it is reasonable to uniquely identify from the FE-SEM images that $\mathrm{Cu}-\mathrm{NP}-\mathrm{TUMBA}$ sample is composed in majority of $\mathrm{CuO}$ nanomaterial in rod shaped structures. The varying thickness of the rods indicates that the small crystallites are aggregated together.

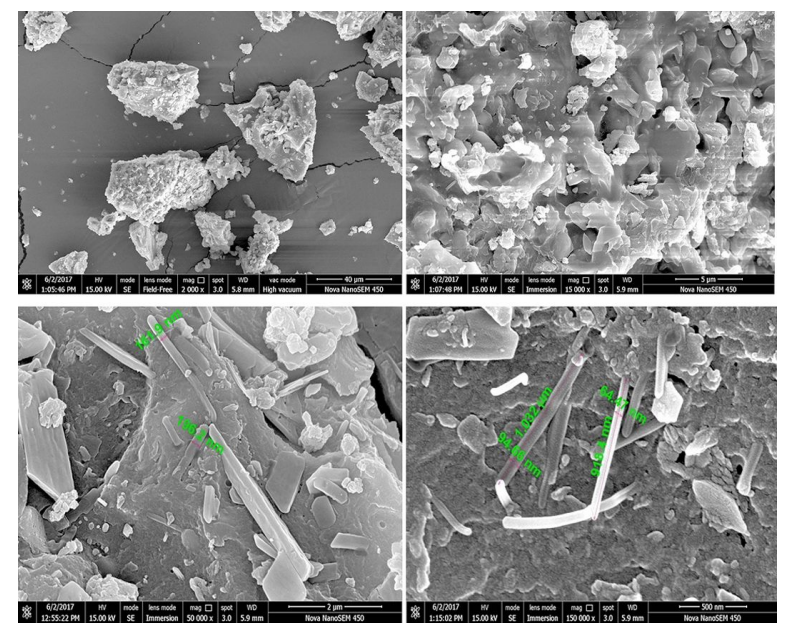

Fig. 3. FE-SEM recorded for Cu-NP-TUMBA at different magnifications.

The morphological properties have a strong influence on the optical and transport properties of the nanostructures [43-45].

\subsection{Estimation of crystallite size}

From the XRD data it could be seen that the main intense peaks were obtained at $\left(\begin{array}{lll}1 & 1 & 0\end{array}\right)$, $\left(\begin{array}{llll}-1 & 1 & 1 / 0 & 0\end{array}\right)$ and ( $\left.\begin{array}{lll}1 & 1 & 1\end{array}\right)$, respectively, corresponding to monoclinic end-centered copper (II) oxide phase. The morphology depicts that the only regular shape of the sample is long cylindrical rod-like structure apart from the irregular aggregates, which suggests the shape factor close to unity. Evaluation of crystallite size using Scherer equation [9, 46] provides values varying from $36 \mathrm{~nm}$ to $39 \mathrm{~nm}$ for the three respective intense peaks. Apart from two major causes, such as size reduction of crystallites and instrumental factors, the microstrain also contributes to peak broadening in XRD pattern. The instrumental factors could be incorporated in Scherer formula while obtaining the FWHM of the peaks. In fact, microstrains are the short range lattice strains resulting from the point defects expelled out to the surface layer of the sample, which could not be separated while estimating the crystallite size using Scherer equation.

For resolving the above ambiguity, WilliamsonHall analysis [47] was performed on XRD data corresponding to the reflection peaks observed for $\mathrm{CuO}$ phase and according to uniform deformation stress model [47, 48], the crystallite size could be separated from microstrain using the equation:

$$
\frac{\beta \cos \theta}{\lambda}=\frac{k}{D}+4 \varepsilon \frac{\sin \theta}{\lambda}
$$

where $\epsilon$ is the microstrain, $\mathrm{k}$ is the shape factor, $\beta$ is the instrumentally corrected full width at half maximum (FWHM) of the main peak under consideration, $\lambda$ is the $\mathrm{X}$-ray wavelength $(1.5406 \AA)$ and $\mathrm{D}$ is the effective crystallite size [9]. It is quite apparent that the above equation can be interpreted using a straight line of the slope, $\epsilon$ and intercept, k/D. The respective plot is shown in Fig. 4.

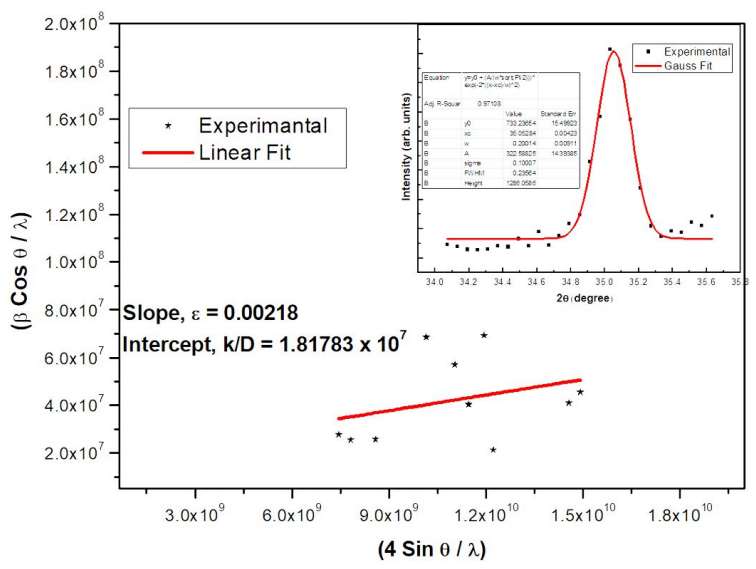

Fig. 4. Williamson-Hall plot of XRD data. The inset shows the Gaussian fit of the main intense peak $\left(\begin{array}{llll}-1 & 1 & 1 / 0 & 0\end{array}\right)$ corresponding to $\mathrm{CuO}$ phase.

From the intercept of straight line fit, the effective crystallite size was estimated to be $55 \mathrm{~nm}$. 
It is apparent from the obtained positive slope (0.00218) that lattice strain has developed in the crystal, which actually caused additional broadening of the peaks. Hence, the average size estimated from Scherer equation became lesser than the effective crystallite size by $\sim 18 \mathrm{~nm}$. Further, the reduced value of the effective crystallite size compared to the size estimated from FE-SEM (rod diameters in $\mathrm{nm}$ ) can be understood in such a way that the morphological size comes from nanostructures (rods and aggregates) surrounded by amorphous defective parts of crystallites as well as organic capping contributed by the leaf extract. Further, the positive strain imparted on core crystallites by the surrounding amorphous layer is also evident from comparatively larger diameter of nanorods as depicted in FE-SEM image (Fig. 3).

\subsection{Estimation of band gap}

Band gap of the sample was estimated from UV-Vis-NIR absorption data obtained using LT-29 spectrophotometer installed at Department of Physics, S.N. College, Punalur, Kerala, India. It is widely understood that depending on the synthesis technique, size, morphology etc., band gap of materials vary from narrow to wide and/or direct to indirect $[49,50]$. The band gap, $\mathrm{E}_{\mathrm{g}}$ can be estimated from the functional relationship between $\alpha \mathrm{h} v$ and photon energy hv, as suggested by Hassanien et al. [50], Tauc et al. [51] and Davis et al. [52]. Depending on the mode of transition, direct or indirect band gaps are possible for transition metal oxides. It is also realized that for perfectly crystalline materials, direct band gap will be higher than indirect band gap [53]. Accordingly, the absorption data obtained for the sample have been plotted for both direct and indirect allowed transition modes and in agreement with XRD result, it was found that the one with best fit and higher value of band gap corresponds to direct transition mode.

Fig. 5 shows the Tauc plot corresponding to direct transition mode for $\mathrm{Cu}-\mathrm{NP}-\mathrm{TUMBA}$. A tangent was drawn to the point of inflection on the curve. Accordingly, two values of the band gap, viz., $1.82 \mathrm{eV}$ and $2.06 \mathrm{eV}$ were estimated for $\mathrm{CuO}$ and $\mathrm{Cu}_{2} \mathrm{O}$, respectively, which qualitatively

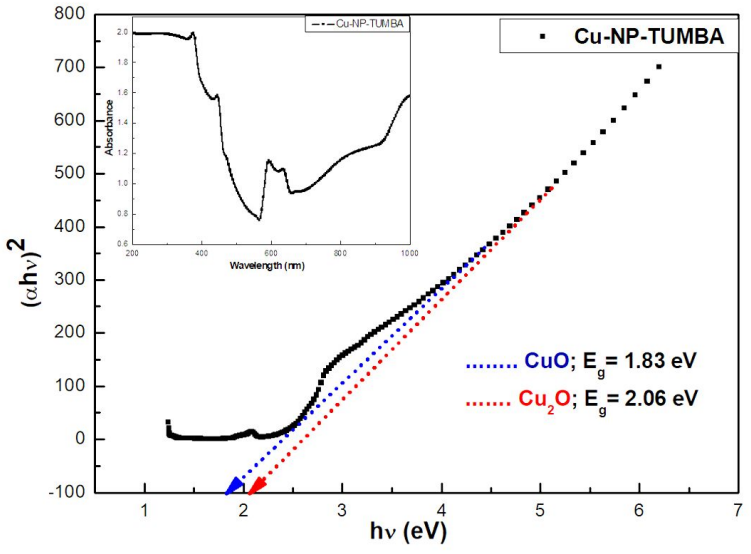

Fig. 5. Tauc plot corresponding to UV-Vis-NIR absorption data in direct transition mode for $\mathrm{Cu}-\mathrm{NP}$ TUMBA. The inset shows the absorption spectrum of the sample.

represents the relative band gap variation for a composite comprising one predominant phase [31, 54]. From the XRD results, it could be seen that $\mathrm{CuO}$ exists as a predominant phase in comparison with $\mathrm{Cu}_{2} \mathrm{O}$ phase in $\mathrm{Cu}-\mathrm{NP}-\mathrm{TUMBA}$ composite sample. In the composite, the fractional quantity of zero valent copper is negligibly small. Further, the band gap of $1.82 \mathrm{eV}$ is found typical as reported for nanocrystalline $\mathrm{CuO}[13,43,53]$ and higher in comparison with monoclinic bulk copper (II) oxide, which is widely identified as p-type semiconductor with narrow band gap of $1.2 \mathrm{eV}$ [13]. This increase in band gap is quite usual because as the size reduces, the continuum in the band structure breaks up and well separated discrete levels develop, and hence, for accommodating such discreteness, the gap widens. For the estimation of band gap values, the band edges with similar slopes were only considered. Any tailing effects below the band gap resulting from phonon-assisted mechanisms were ignored. This was done to a certain extent due to the varied and dissimilar slopes, compared to that at two prominent edges as shown in Fig. 5 [31, 55].

\subsection{Thermogravimetric analysis (TGA)}

Fig. 6 presents thermogravimetric analysis curve recorded using TGA-50 detector installed 
at CEPCI Laboratory, Kollam, Kerala, India. The heating was performed in air atmosphere at a flow rate of $50 \mathrm{~mL} / \mathrm{min}$ and up to temperature of $700{ }^{\circ} \mathrm{C}$. From the curve, it can be seen that the sample heated up to $94.5^{\circ} \mathrm{C}$ undergoes a total weight loss of $0.304 \mathrm{mg}(4.34 \%)$, which is attributed to the liberation of moisture adsorbed on the surface of the sample. Further $0.240 \mathrm{mg}$ loss up to $240.6{ }^{\circ} \mathrm{C}$ is endorsed by elimination of volatile components present in the sample. The decomposition step between $240.6{ }^{\circ} \mathrm{C}$ and $464{ }^{\circ} \mathrm{C}$ is generally ascribed to the elimination of carbon group compounds present in the sample, and here, in particular, to the capping of phytochemical components over the nanoparticles.

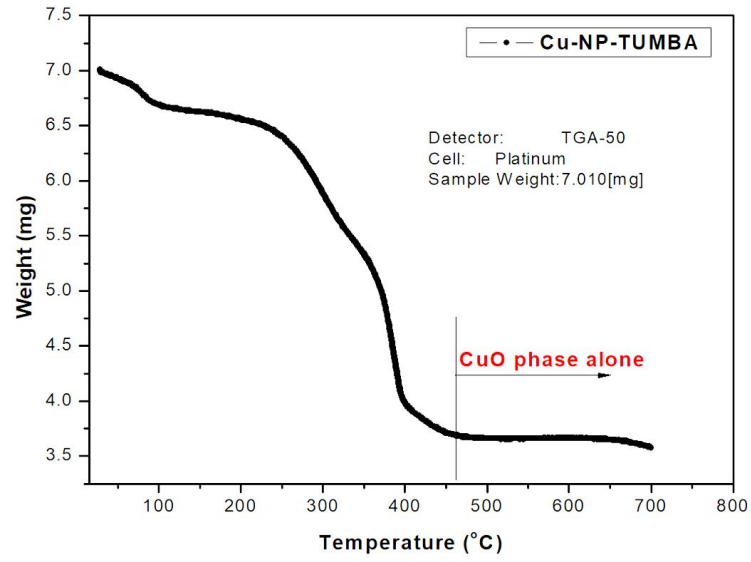

Fig. 6. TGA curve obtained for Cu-NP-TUMBA.

One of the phytochemicals contained in the sample, such as alkaloid, phytosterol, flavonoid, saponin, phenol or glycoside [42], was supposed to serve as reductant and steric stabilizer. In fact, the stabilization functionalizes the nanocrystal surfaces and prevents in general flocculation of small particles. At $464{ }^{\circ} \mathrm{C}$, the weight loss becomes $3.335 \mathrm{mg}(47.58 \%)$. The final step between $464^{\circ} \mathrm{C}$ and $700{ }^{\circ} \mathrm{C}$ in the curve is represented by a flat horizontal line wherein the weight loss becomes negligible. Appearance of any peaks or dips in this segment is indicative of any phase transformations in the core crystal structure. Thus, the flat segment between $464{ }^{\circ} \mathrm{C}$ and $700{ }^{\circ} \mathrm{C}$ in the curve reveals the absence of any significant phase transformation in the crystal. In the presence of plant reducing agent, the $\mathrm{Cu}^{2+}$ ions in the precursor salt reduced to $\mathrm{Cu}^{1+}$ and $\mathrm{Cu}^{0}$ [56]. It is obvious that oxidation of $\mathrm{Cu}_{2} \mathrm{O}$ and $\mathrm{Cu}^{0}$, respectively to $\mathrm{CuO}$ has occurred during the heating process, which predominantly happens at temperatures from $400{ }^{\circ} \mathrm{C}$ to $464{ }^{\circ} \mathrm{C}$ [56]. It is thus reasonable to infer that $\mathrm{Cu}-\mathrm{NP}-\mathrm{TUMBA}$ is composed of crystalline phase of $\mathrm{CuO}$ alone at temperature above $464{ }^{\circ} \mathrm{C}$, at least up to $700{ }^{\circ} \mathrm{C}$.

\section{Conclusions}

Nanostructured and monoclinic end-centered crystallites of $\mathrm{CuO}$ along with secondary $\mathrm{Cu}_{2} \mathrm{O}$ phase and traces of zero-valent copper have been successfully synthesized by the chemical reduction of $\mathrm{CuSO}_{4} \cdot 5 \mathrm{H}_{2} \mathrm{O}$ using phytochemicals present in the leaf extract of Leucas aspera. The formation of rod shaped $\mathrm{CuO}$ phase and direct optical transition mode were identified in the sample. The band gaps viz., $1.82 \mathrm{eV}$ and $2.06 \mathrm{eV}$ were estimated respectively, for $\mathrm{CuO}$ and $\mathrm{Cu}_{2} \mathrm{O}$ phases in the sample. The thermal analysis revealed the fractional ingredients such as moisture, volatile components and inorganic core crystallites present in the sample. In fact, the heating could facilitate the oxidative transition of fractional phases of $\mathrm{Cu}_{2} \mathrm{O}$ and $\mathrm{Cu}^{0}$ into $\mathrm{CuO}$ single phase, and at temperature above $464{ }^{\circ} \mathrm{C}$, the sample was found to be composed of a single crystallite phase of $\mathrm{CuO}$ alone.

\section{Acknowledgements}

The author is thankful to the Principal, TKMMC Nangiarkulangara and SNC Punalur; DST-FIST SNC Punalur and MSc students at the SNC Punalur, namely Akhil (2014-16 batch) and Reshma (2015-17 batch) for the supports in various stages that led to the fruitful completion of this work.

\section{References}

[1] Li S.K, Pan Y.Y, Wu M., Huang F.Z, Li C.H., SHEN Y.H., Appl. Surface Sci., 315 (2014), 169.

[2] Zhou H., Wong S.S., ACS Nano, 2 (2008), 944.

[3] Mashock M., Yu K., Cui S., Mao S., Lu G., CHEN J., ACS Appl. Mater. Interfaces, 4 (2012), 4192.

[4] WANG P., NG Y.H., AMAL R., Nanoscale, 5(2013), 2952.

[5] Jung S., Yong K., Chem. Commun., 47(2011), 2643.

[6] Park J.C., Kim J., Kwon H., Song H., Adv. Mater., 21 (2009), 803.

[7] Yin Z., Wang Z., DU Y., QI X., HuAnG Y., XuE C., ZHANG H., Adv. Mater., 24 (2012), 5374. 
[8] Prasad A.S, Mater. Sci. Semicond. Process., 53 (2016) 79.

[9] Prasad A.S., Mater. Sci. Semicond. Process., 71 (2017), 342

[10] Nasrollahzadeh M., Maham M., SaJadi S.M., J. Colloid Interface Sci., 455 (2015), 245.

[11] Nasrollahzadeh M., Sajadi M.S., RostamiVARTOOni A., J. Colloid Interface Sci., 459 (2015), 183.

[12] Xia Y., Yang P., Sun Y., Wu Y., Mayers B., Gates B., Yin Y., Kim F., YAn H., Adv. Mater, 15(2003), 353.

[13] Dhineshbabu N.R., Rajendran V., Nithyavarthy N., Vetumperumal R., Appl. Nanosci., 6(2016), 933.

[14] Feng Y.Z., Zheng X.L., Nano Lett., 10 (2010), 4762.

[15] CaO J.L., ShaO G.S., WANG Y., LiU Y.P., YUAN Z.Y., Catal. Commun., 9 (2008), 2555.

[16] Xu L., Sithambaram S., Zhang Y., Chen C., JIN L., Chem. Mater., 21 (2009), 1253.

[17] Yang M., He J., Hu X., Yan C., Cheng Z., Environ. Sci. Technol., 45 (2011), 6088.

[18] Wang G.L., Huang J.C., Chen S.L., Gao Y.Y., CAO D.X., J. Power Sources, 196 (2011),5756.

[19] Chaudhary Y.S., Agrawal A., Shrivastav R., SATSANGI V.R., DASS D., Int. J. Hydrogen Energ., 29 (2004), 131.

[20] Kaur G., Saini K., Tripathi A.K., Jain V., DEVA D., Vacuum, 139 (2017),136.

[21] JiAng X., Herricks T., XiA Y., Nano Lett., 2 (2002), 1333.

[22] Liu B., Zeng H.C., J. Am. Chem. Soc., 126 (2004), 8124.

[23] Xu L., Sithambaram S., Zhang Y., Chen C.H., Jin L., Joesten R., Suib S.L., Chem. Mater., 21 (2009), 1253

[24] Yu X.Y., Xu R. X., Gao C., Luo T., Jia Y., LiU J.H., HUANG X.J., ACS Appl. Mater. Interfaces, 4 (2012), 1954

[25] Gao D., Yang G., Li J., Zhang J., Zhang J., Xue D., J. Phys. Chem. C, 114 (2010), 18347.

[26] Wang H., Shen Q., Li X., LiU F., Langmuir, 25 (2009), 3152.

[27] Zhang Q., Zhang K., Xu D., Yang G., Huang H., NiE F., LiU C., Yang S., Prog. Mater. Sci., 60 (2014),208.

[28] Gao S., Yang S., Shu J., Zhang S., Li Z., JiAng K., J. Phys. Chem. C, 112 (2008),19324.

[29] Sonia S., JaYram N.D., Kumar S.P., Mangalaraj D., Ponpandian N., Viswanathan C., Super Latt. Microstruct., 66 (2014), 1.

[30] Yang C., Su X., Xiao F., Jian J., Wang J., Sensor. Actuat. B, 158 (2011), 299.

[31] Wu H.W., Lee S.Y., Lu W.C., Chang K.S., Appl. Surface Sci., 344 (2015), 236.
[32] Yu L., Zhang G., Wu Y., Bai X., Guo D., J. Cryst. Growth, 310 (2008), 3125.

[33] Wang H., Xu J.Z., Zhu J.J., Chen H.Y., J. Cryst. Growth, 244 (2002), 88.

[34] Tang X.L., Ren L., Sun L.N., Tian W.G., CaO M.H., Hu C.W., Chem. Res. Chinese U, 22 (2006), 547.

[35] Zhang H., Li S., M X., Yang D., Mater. Res. Bull. 43(2008), 1291.

[36] Siegfried M.J., Choi K.S., Angew. Chem. Int. Ed., 44 (2005), 3218

[37] Kuo C.H., Chen C.H., Huang M H., Adv. Funct. Mater., 17 (2007), 3773

[38] LiU B., Zeng H.C., J. Am. Chem. Soc., 126 (2004), 8124.

[39] LiU J., Xue D., Adv. Mater., 20 (2008), 2622.

[40] Zhu G., Xu H., Xiao Y., LiU Y., Yuan A., Shen X., ACS Appl. Mater. Interfaces, 4 (2012), 744.

[41] JiAng X., Herricks T., XiA Y., Nano Lett., 2 (2002), 1333

[42] Latha. B, Rumaisa. Y, Soumya. C.K, Shahul S. S ADHIYA N., J. Chem. Pharma. Res., 5(4)(2013),222.

[43] Sagaya J., Arockiasamy K., Irudayaraj J., Ceram.Int., 42 (2016), 6198.

[44] Mageshwari K., Sathyamoorthy R., Appl. Nanosci., 3 (2013), 161.

[45] Liu C., Cheng Q., Zheng J., YAng T., IEEE Image and Signal Processing, (2009).

[46] Cullity B.D., Elements of X-ray diffraction, AddisonWesley, Reading, 1978.

[47] Williamson G.K., Hall W.H., Acta Metall., 1 (1953), 22.

[48] Biju V., Sugathan N., VRinda V., Salini S.L., J. Mater. Sci., 43 (4) (2008), 1175.

[49] Bhattacharya D., Chaudhuri S., Pal A.K., Vacuum, 43 (1992), 313

[50] Hassanien A.S., AKL A.A., Superlattices Microstruct., 89 (2016), 153.

[51] Tauc J., Grigorovici R., Vancu A., Phys. Status Solidi, 15 (1966), 627.

[52] Davis E.A., Mott N.F., Philos. Magn., 22 (1970), 903.

[53] Radhakrishnan A.A., Beena B.B., Indian J. Adv. Chem. Sci., 2 (2014), 158.

[54] Leonard K.C., Nam K.M., Lee H.C., Kang S.H., PARK H.S., BArd A.J., J. Phys. Chem. C, 117 (2013), 15901.

[55] Schubert E.F., Light-Emitting Diodes, $2^{\text {nd }}$ ed., Cambridge University Press, Cambridge, 2006.

[56] Nasrollahzadeh M., Mahamb M., SaJadi S.M., J. Colloid. Interface Sci., 455 (2015), 245.

Received 2019-01-08 Accepted 2019-04-23 